\title{
Signet Ring Cells and Efficacy of First-line Chemotherapy in Advanced Gastric or Oesogastric Junction Adenocarcinoma
}

\author{
NATHALIE LEMOINE ${ }^{1}$, ANTOINE ADENIS ${ }^{2}$, OLIVIER BOUCHE ${ }^{3}$, \\ ALAIN DUHAMEL ${ }^{4}$, ALEXANDRA HEURGUE $^{3}$, EMMANUELLE LETEURTRE $^{5}$, \\ ERIC AMELA ${ }^{2}$, JULIA SALLERON ${ }^{4}$ and MOHAMED HEBBAR ${ }^{1}$ \\ ${ }^{1}$ Department of Medical Oncology, University Hospital, Lille, France; \\ ${ }^{2}$ Department of Digestive Oncology, Oscar Lambret Centre, Lille, France; \\ ${ }^{3}$ Department of Digestive Oncology, University Hospital, Reims, France; \\ ${ }^{4}$ Department of Biostatistics, EA2694, University Lille Nord de France, University Hospital, Lille, France; \\ ${ }^{5}$ Department of Pathology, University Lille Nord de France, University Hospital, Lille, France
}

\begin{abstract}
Aim: To evaluate the efficacy of first-line palliative chemotherapy, regarding the presence of signet ring cells (SRC). Patients and Methods: Retrospective analysis of consecutive patients with locally advanced or metastatic gastric or oesogastric junction adenocarcinoma who received first-line chemotherapy. Response to chemotherapy, progression-free survival (PFS) and overall survival (OS) were compared between SRC and non-SRC (NSRC) groups. Results: Two hundred and three patients were treated, with 57 (28\%) having SRC adenocarcinoma. Objective response rate was significantly lower in SRC patients $(5.3 \%$ vs. $28.1 \%, p=0.0004)$. PFS was not significantly different between SRC and NSRC patients (median=3.8 vs. 4.9 months, $p=0.07$ ). OS was significantly shorter in SRC patients (median=5.6 vs. 9.4 months, $p<0.008$ ). In multivariate analysis SRC was not an independent prognostic factor for $O S$ (hazard ratio $(H R)=1.28, p=0.15)$. Conclusion: Patients with advanced SRC adenocarcinomas seemed to benefit less from chemotherapy, whereas the presence of SRC was not an independent survival prognostic factor.
\end{abstract}

Despite an important decrease of its incidence and mortality, gastric cancer remains the fourth most common cancer and the second leading cause of cancer-related deaths worldwide (13 ). Approximately two thirds of patients have locally advanced

Correspondence to: Professor Mohamed Hebbar, $\mathrm{MD}, \mathrm{PhD}$, Service d'Oncologie Médicale, Centre Hospitalo-Universitaire, 1 rue Michel Polonovski, 59037 Lille, France. Tel +33 320445461, Fax +33 320445023,e-mail: mohamed.hebbar@chru-lille.fr

Key Words: Signet ring cells, gastric adenocarcinoma, oesogastric junction adenocarcinoma, prognosis. or metastatic disease at diagnostics (4). About $90 \%$ of gastric tumours are adenocarcinomas that are divided into two types according to Lauren's classification (5): intestinal and diffuse types, with the latter including signet ring cell (SRC) adenocarcinoma. SRC is a histological term used to describe a form of mucin-secreting adenocarcinoma whose isolated cells contain abundant cytoplasmic mucin, pushing the nucleus to one side. The World Health Organization (WHO) classification defines SRC when these mucin-rich isolated cells represent more than $50 \%$ of the tumour cells (6).

The incidence of SRC adenocarcinoma is increasing for thirty years in Western countries, conversely to the intestinal type (7-10). The specific prognosis of SRC adenocarcinoma remains controversial. Several non-comparative retrospective studies indicated a better prognosis in case of SRC (11-13). Other retrospective studies indicated a poor prognosis of SRC in all (14) or only in advanced stages $(15,16)$. Some studies indicated that presence of SRC was not an independent prognostic factor $(17,18)$.

It is commonly considered that SRC adenocarcinoma is less sensitive to chemotherapy, by comparison to intestinal gastric adenocarcinoma. In a recent study performed in patients with localized gastric adenocarcinoma, preoperative chemotherapy was associated with a worse prognosis in patients with SRC (19). We here present the results of a retrospective study assessing the efficacy of chemotherapy in advanced stages. We compared results of chemotherapy in patients with locally advanced or metastatic gastric adenocarcinoma, regarding the presence or not of SRC.

\section{Patients and Methods}

Patients. The eligibility criteria included histologically documented adenocarcinoma of the stomach or the oesogastric junction; metastatic or locally advanced non resectable disease; and a WHO 
performance status $\leq 2$. Patients have been included in three centres in Northern France. The Ethics committee of the University Hospital of Lille, France, has been informed of the realization of this non-interventional study.

The criteria of the WHO classification for histologic typing of gastric tumours were used: SRC adenocarcinoma was defined as "an adenocarcinoma in which a predominant component (more than $50 \%$ of the tumour cells) is represented by isolated or small groups of malignant cells containing intracytoplasmic mucin"(6). Tumours with minority SRC (less than $50 \%$ of the tumour) were not considered as SRC adenocarcinoma.

After informed consent, all patients received first-line chemotherapy. Chemotherapy regimens included EOX (epirubicin, oxaliplatin and capecitabine), ECX (epirubicin, cisplatin and capecitabine), ECF (epirubicin, cisplatin and 5-fluorouracile (5-FU)), FOLFIRI (5-FU, leucovorin and irinotecan), FOLFOX (5-FU, leucovorin and oxaliplatin), 5-FU-cisplatin, docetaxel and 5-FU alone. Tumour evaluations were performed by computed tomography (CT) scan every three cycles (EOX, ECX, ECC, cisplatin-5-FU regimens) or every 4 cycles (FOLFIRI, FOLFOX regimens). Tumour responses were graded according to the RECIST criteria (20). Chemotherapy was carried on until disease progression, limitative toxicity or patient's refusal. After cessation of first-line chemotherapy, subsequent chemotherapy lines were allowed. All patients were seen at least every two months for clinical and CT scan evaluations thereafter. Follow-up of the study was conducted until death or until the cut-off date of October 30, 2011.

Study end-points. The primary end-point was overall survival (OS). Secondary end-points were progression-free survival (PFS), objective response rate (ORR) according to RECIST criteria and safety according to the National Cancer Institute-common toxicity criteria (NCI-CTC) (21).

We assessed the potent prognostic value of the presence of SRC and the following baseline clinicopathological features: age, gender, performance status, primary tumour location, prior gastrectomy, prior perioperative or adjuvant chemotherapy and/or adjuvant radiotherapy, tumour differentiation, tumour stage at diagnosis and at the beginning of palliative chemotherapy (locally advanced or metastatic), number of disease sites, presence of peritoneal carcinosis, type of chemotherapy (with our without platinum compound).

Statistical analyses. The results were expressed by means and standard deviations (SD) for continuous variables and by frequencies and percentages for categorical variables. The two groups defined by the presence or the absence of SRC were compared by using the unpaired Student's $t$-test for continuous variables and by the Chi-square test or Fisher's exact test for categorical variables. OS was calculated from the beginning of palliative chemotherapy until death when it occurred. When death did not occur, the observation was censored at the time of the cutoff date (October 30, 2011). For PFS, the event was the death from any cause or disease progression. The survival curves were estimated by using the Kaplan-Meier method. The individual prognostic value of each baseline clinic-pathologic feature was studied by using the Cox proportional hazards model (univariate analysis). These variables were then introduced in a multivariate Cox regression model with backward selection significant at the 0.1 level. In this regression model, tumour differentiation was not analyzed due to missing data and the SRC status was included in every model. Hazard ratios (HRs) and their 95\% confidence intervals (CIs) were computed. Statistical analysis was performed by means of SAS 9.3 software (SAS Institute Inc., Cary, NC, USA). All tests were two-sided and statistical significance was defined as a $p$-value $\leq 0.05$.

\section{Results}

Patients' characteristics. Between January 2003 and June 2011, 203 patients were included in this study. Among them, $27(13 \%)$ had locally advanced disease and $176(87 \%)$ metastatic disease. Eighty-eight patients (43.4\%) had oesogastric tumour and 115 patients $(56.6 \%)$ gastric tumour. Among the 203 patients, 57 patients (28\%) had a histological diagnosis of SRC adenocarcinoma.

The clinicopathologic features of the 57 patients with SRC gastric cancer and of the 146 patients with non-signet ring cell (NSRC) adenocarcinoma are presented in Table I. The SRC patients were significantly younger (mean age $=53 \mathrm{vs}$. 61 years; $p<0.001)$. The proportion of females in the SRC group was higher $(46 \%$ vs. $14 \% ; p<0.001)$. SRC tumours were more frequently located in the lower third of the stomach than NSRC tumours (37\% vs. 22\%; $p=0.03)$. Diffuse location was more frequent in the SRC group $(14 \%$ vs. $1 \% ; p<0.001)$. The peritoneal carcinosis was significantly more common in SRC adenocarcinomas (68.4\% vs. $30.8 \%$; $p<0.001)$. SRC tumours were more frequently poorly differentiated ( $89 \%$ vs. $36 \%$; $p<0.001)$. Significantly, more patients in the SRC group previously underwent curative surgery ( $54 \%$ vs. $36 \% ; p=0.02)$.

There were no significant differences between SRC and NSRC adenocarcinoma regarding the tumour stage at diagnosis and at the beginning of the palliative chemotherapy, regarding (i) the performance status and the number of metastatic sites at the beginning of the palliative chemotherapy, (ii) previous perioperative or adjuvant chemotherapy and/or radiotherapy, (iii) the proportion of patients who had received chemotherapy with platinum and (iv) the proportion of patients who were dead at the cut-off date. In SRC adenocarcinoma, the firstline chemotherapy regimens were FOLFIRI (26\%), ECC (14\%), EOX (14\%), 5-FU-cisplatin (11\%), ECF (9\%), FOLFOX (7\%), docetaxel (3\%) and others (16\%). In NSRC group, the regimens were FOLFIRI (30\%), 5-FUcisplatin $(21 \%)$, ECC $(10 \%)$, ECF $(9 \%)$, EOX $(8 \%)$, FOLFOX (7\%), LV5-FU2 (4\%), capecitabine-cisplatin (3\%) and others (8\%). The median numbers of administered chemotherapy cycles were 7 and 7 in SRC and NSRC adenocarcinoma, respectively.

Forty-three percent of all patients received second-line chemotherapy: $35 \%$ in the SRC group and $46 \%$ in the NSRC group. 
Table I. Baseline patients' characteristics regarding the presence or not of signet ring cells (SRC or NSRC groups).

\begin{tabular}{|c|c|c|c|}
\hline & $\begin{array}{c}\text { SRC } \\
\mathrm{n}=57(28 \%)\end{array}$ & $\begin{array}{c}\text { NSRC } \\
\mathrm{n}=146(72 \%)\end{array}$ & $p$-Value \\
\hline Male gender & $31(54.4)$ & $126(86.3)$ & $<0.001$ \\
\hline Mean age (years) (standard deviation) & $52.8(14.8)$ & $61.3(12.3)$ & $<0.001$ \\
\hline Disease status at the diagnosis & & & 0.08 \\
\hline Located/resectable & $14(24.6)$ & $22(15.1)$ & \\
\hline Locally advanced & $10(17.5)$ & $46(31.5)$ & \\
\hline Metastatic & $33(57.9)$ & $78(53.4)$ & \\
\hline Tumour location & & & $<0.001$ \\
\hline Upper & $16(28.1)$ & $86(58.9)$ & \\
\hline Middle & $12(21.1)$ & $27(18.5)$ & \\
\hline Lower third of stomach & $21(36.8)$ & $32(21.9)$ & \\
\hline Tumour differentiation & & & $<0.001$ \\
\hline Weakly & $25(89.3)$ & $43(36.4)$ & \\
\hline Averagely & $3(10.7)$ & $56(47.5)$ & \\
\hline Well & 0 & $19(16.1)$ & \\
\hline Unknown & \multicolumn{2}{|c|}{$57(28)$} & \\
\hline Disease status at advanced stage & & & 0.1 \\
\hline Locally advanced & $4(7.0)$ & $23(15.8)$ & \\
\hline Metastatic & $53(93.0)$ & $123(84.3)$ & \\
\hline Prior surgery of the primary & $31(54.4)$ & $52(35.6)$ & 0.02 \\
\hline Perioperative chemotherapy & $11(19.3)$ & $31(21.2)$ & NS \\
\hline Performance status (advanced stage) & & & NS \\
\hline Performance status (advanced stage) & & & NS \\
\hline 0 & $15(26.3)$ & $42(28.8)$ & \\
\hline 1 & $28(49.1)$ & $81(55.5)$ & \\
\hline 2 & $14(24.6)$ & $23(15.8)$ & \\
\hline Number of metastatic sites & & & NS \\
\hline $0-1$ & $29(50.8)$ & $78(53.4)$ & \\
\hline$\geq 2$ & $28(49.1)$ & $68(46.6)$ & \\
\hline Peritoneal carcinosis & $39(68.4)$ & $45(30.8)$ & $<0.001$ \\
\hline Platinum-based first-line chemotherapy & $35(61.4)$ & $94(64.4)$ & NS \\
\hline
\end{tabular}

NS, Not significant.

Overall survival. The median and mean follow-up durations were 8.2 and 13.0 months (range=1-129). OS was significantly shorter in the SRC group: 5.6 vs. 9.4 months $(p=0.008$; Figure 1). In the univariate analysis, a significant difference for OS was found for performance status (PS $2 \mathrm{vs}$. 0 : $\mathrm{HR}=3.04, p<0.001$; PS 3 vs. $0: \mathrm{HR}=5.35, p=0.002$ ), disease stage at the beginning of chemotherapy $(\mathrm{HR}=1.91$, $p=0.01)$, age $(\mathrm{HR}=0.99, p=0.044)$ and $\mathrm{SRC}$ adenocarcinoma $(\mathrm{HR}=1.55, p=0.01$ (Table II). In the multivariate analysis, performance status (PS 3 vs. 0: $\mathrm{HR}=6.27, p<0.001$; PS $2 v s$. $0: \mathrm{HR}=2.54, p=0.0002$; PS 1 vs. $0: \mathrm{HR}=1.43, p=0.044)$ and metastatic stage at the beginning of the palliative chemotherapy $(\mathrm{HR}=2.15, \quad p=0.002)$ were predictive independent factors of poor prognosis (Table III). SRC was not an independent prognostic factor $(\mathrm{HR}=1.28, p=0.15)$.

Progression-free survival. The median PFS of patients with SRC adenocarcinoma was shorter than that of patients with NSRC; however, the difference was not significant (3.8 vs.

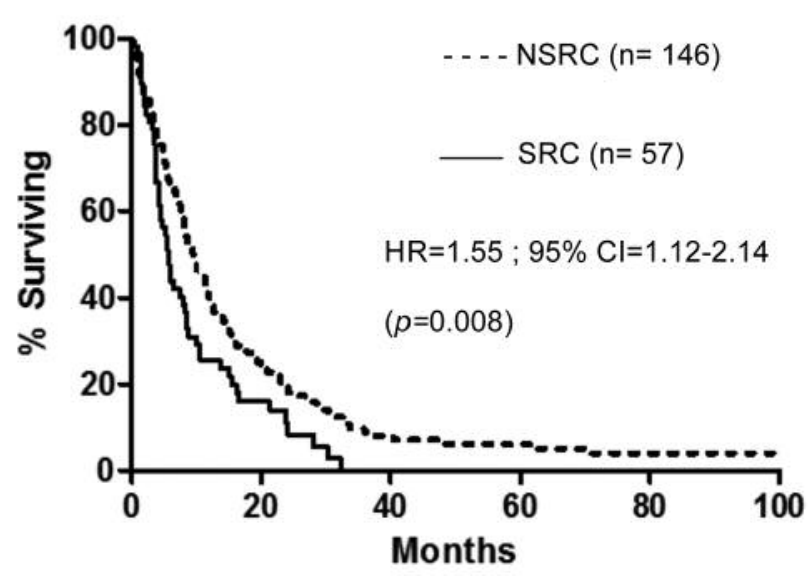

Figure 1. Overall survival in patients with signet ring cell (SRC) or nonsignet ring cell (NSRC) adenocarcinomas. HR, Hazard ratio; CI, confidence interval. 
Table II. Univariate analysis of potent prognostic factors for progression-free survival (PFS) and overall survival (OS).

\begin{tabular}{|c|c|c|c|c|c|c|}
\hline \multirow[b]{2}{*}{ Factors } & \multicolumn{3}{|c|}{ PFS } & \multicolumn{3}{|c|}{ OS } \\
\hline & Hazard ratio & $95 \% \mathrm{CI}$ & $p$-Value & Hazard ratio & $95 \% \mathrm{CI}$ & $p$-Value \\
\hline \multicolumn{7}{|l|}{ Gender } \\
\hline Female/Male & 1.16 & $0.83-1.62$ & NS & 1.38 & $0.98-1.94$ & 0.07 \\
\hline Age (years) & 0.99 & $0.98-1.00$ & 0.04 & 0.99 & $0.98-1.00$ & 0.044 \\
\hline \multicolumn{7}{|l|}{ Tumour location } \\
\hline Upper & 1 & & & 1 & & \\
\hline Middle & 1.26 & $0.86-1.85$ & NS & 1.50 & $0.95-2.37$ & 0.08 \\
\hline Lower third of stomach & 0.97 & $0.69-1.36$ & NS & 1.25 & $0.83-1.88$ & NS \\
\hline Diffuse & 1.23 & $0.62-2.44$ & NS & 1.98 & $0.62-6.32$ & NS \\
\hline \multicolumn{7}{|l|}{ Signet ring cells } \\
\hline Yes/No & 1.33 & $0.98-1.82$ & 0.07 & 1.55 & $1.12-2.14$ & 0.01 \\
\hline \multicolumn{7}{|l|}{ Tumour differentiation } \\
\hline Averagely/Weakly & 1.02 & $0.71-1.47$ & NS & 0.83 & $0.58-1.21$ & NS \\
\hline Well/Weakly & 1.08 & $0.64-1.82$ & NS & 0.79 & $0.45-1.36$ & NS \\
\hline \multicolumn{7}{|l|}{ Disease extent } \\
\hline Metastatic/Locally advanced & 1.57 & $1.01-2.44$ & 0.04 & 1.91 & $1.22-3.01$ & 0.01 \\
\hline \multicolumn{7}{|l|}{ Prior surgery for primary } \\
\hline No/Yes & 1.14 & $0.86-1.53$ & NS & 1.10 & $0.78-1.56$ & NS \\
\hline \multicolumn{7}{|l|}{ Perioperative chemotherapy } \\
\hline Yes/No & 1.09 & $0.77-1.55$ & NS & 1.10 & $0.76-1.57$ & NS \\
\hline \multicolumn{7}{|l|}{ Performance status (vs. 0) } \\
\hline 1 & 1.16 & $0.83-1.62$ & NS & 1.31 & $0.87-1.96$ & NS \\
\hline 2 & 1.86 & $1.17-2.89$ & 0.01 & 3.04 & $1.74-5.31$ & $<0.001$ \\
\hline \multicolumn{7}{|l|}{ Number of metastatic sites } \\
\hline$\geq 2 / 0-1$ & 1.03 & $0.77-1.37$ & NS & 1.19 & $0.89-1.59$ & NS \\
\hline \multicolumn{7}{|l|}{ Peritoneal carcinosis } \\
\hline Yes/No & 1.21 & $0.91-1.62$ & 0.19 & 1.47 & $1.09-1.97$ & 0.01 \\
\hline \multicolumn{7}{|l|}{ Platinum-based chemotherapy } \\
\hline Yes/No & 0.87 & $0.65-1.17$ & NS & 0.89 & $0.66-1.20$ & NS \\
\hline
\end{tabular}

NS, Not significant; CI, confidence interval.

Table III. Multivariate analysis of potent prognostic factors for progression-free survival (PFS) and overall survival (OS).

\begin{tabular}{|c|c|c|c|c|c|c|}
\hline \multirow[b]{2}{*}{ Factors } & \multicolumn{3}{|c|}{ PFS } & \multicolumn{3}{|c|}{ OS } \\
\hline & Hazard Ratio & $95 \% \mathrm{CI}$ & $p$-Value & Hazard Ratio & $95 \% \mathrm{CI}$ & $p$-Value \\
\hline \multicolumn{7}{|l|}{ Signet ring cells } \\
\hline Yes/No & 1.14 & $0.82-1.58$ & 0.44 & 1.28 & $0.91-1.80$ & 0.15 \\
\hline \multicolumn{7}{|l|}{ Disease status* } \\
\hline Metastatic/Locally advanced & 1.63 & $1.02-2.62$ & 0.043 & 2.15 & $1.31-3.51$ & 0.002 \\
\hline \multicolumn{7}{|l|}{ Performance status (vs. 0$)$} \\
\hline 1 & 1.26 & $0.90-1.77$ & 0.18 & 1.43 & $1.01-2.04$ & 0.044 \\
\hline 2 & 1.92 & $1.18-3.11$ & 0.009 & 2.54 & $1.55-4.19$ & $<0.001$ \\
\hline
\end{tabular}

*At the beginning of palliative chemotherapy. CI, Confidence interval.

4.9 months, $p=0.07)$. In the univariate analysis, performance status (PS 3 vs. 0 : HR=3.38, $p=0.001$; PS 2 vs. 0 : $\mathrm{HR}=1.84$, $p=1.84$ ) and disease stage at the beginning of chemotherapy (HR=1.57, $p=0.044)$ were also found to be prognostic factors for PFS (Table II). Multivariate analysis indicated that performance status (PS 3 vs. 0: $\mathrm{HR}=3.39, p=0.001$; PS $2 v s$. 0 : $\mathrm{HR}=1.92, p=0.009$; PS 1 vs. $0: \mathrm{HR}=1.26, p=0.18$ ) and disease stage at the beginning of chemotherapy (HR $=1.63$, $p=0.043$ ) were independent prognostic factors for PFS (Table III). 
Objective response rate. ORR to the first-line chemotherapy was significantly higher in NSRC adenocarcinoma $(28.1 \%$ vs. $5.3 \%, p<0.001)$. In SRC and NSRC adenocarcinoma, complete response was observed in 0 and $6 \%$, partial response in $5 \%$ and $22 \%$, stable disease in $42 \%$ and $32 \%$, disease control in $60 \%$ and $47 \%$ and progressive disease in $53 \%$ and $40 \%$, respectively.

Safety. Anaemia, thrombocytopenia and neutropenia of grades 3 and 4 were observed in $6 \%, 4 \%$ and $11 \%$, respectively. Nausea and vomiting, diarrhoea, anorexia and peripheral neuropathy of grades 3 and 4 were found in 5\%, $4 \%, 1 \%$ and $2 \%$, respectively. There was no significant difference in frequency of adverse events between SRC and NSRC adenocarcinomas.

\section{Discussion}

This study showed that SRC adenocarcinoma was associated with a lower response rate to chemotherapy and a lower OS, but this prognostic value was not independent in multivariate analyses. The survival benefit of palliative chemotherapy has been demonstrated since the 1990s $(22,23)$ and confirmed by the meta-analysis of Wagner et al. (24) in 2010. Similarly, the interest of perioperative chemotherapy in localized gastric and oesogastric adenocarcinomas has been demonstrated with a significant gain in terms of OS (25). Yet, these studies have not distinguished SRC from NSRC adenocarcinomas. Recently, a retrospective study has questioned the benefit of perioperative chemotherapy for patients with SRC adenocarcinomas (19). In locally advanced or metastatic disease, only few studies focused specifically on SRC adenocarcinomas. Our findings are consistent with those recently reported by Taghavi et al. reviewing 10,246 cases of patients with gastric cancer in the National Cancer Institute Surveillance, Epidemiology and End Results database, including 2,666 SRC adenocarcinomas in the United States (26). In their multivariate analysis, presence of SRC was not an independent mortality predictor $(\mathrm{HR}=1.05 ; \quad p=0.15)$. Median survival for SRC adenocarcinoma $v s$. NSRC adenocarcinoma was not significantly different for stage 2 (40.0 vs. 30.0 months; $p=0.194)$ and stage 3 (20.0 vs. 19.0 months; $p=0.671)$ diseases. Yet, for stage 4 tumours, NSRC adenocarcinoma had a mildly shorter median OS than SRC adenocarcinoma (6.0 vs. 7.0 months; $p=0.01$ ). The performance status of patients, number of metastatic sites and number of stage 4 patients whose condition was consistent with the achievement of chemotherapy were not described. An imbalance in these characteristics may explain this difference, which, however, remains small.

As in Asian and American studies (11, 26-30), SRC cancer had a different presentation. SRC adenocarcinoma was more frequent in females and in younger patients. Location in the stomach was more controversial. In our study, SRC adenocarcinoma was more frequent in the lower third of the stomach. This preferential distribution has come across in a recent study (26). SRC adenocarcinoma was more likely to be found in the middle third of the stomach, in other studies from Asia $(11,29,30)$. Similarly, the prognostic value of SRC adenocarcinoma seems different in Asian studies. In several Asian studies, patients with early SRC gastric adenocarcinoma had a better survival than patients with NSRC adenocarcinoma $(11,12,15-17,29)$ and those with advanced SRC adenocarcinoma had a similar (11, 12, 30, 31) or poorer $(15,16)$ prognosis than NSRC adenocarcinoma. In contrast, Theuer et al., who studied a historical cohort of consecutive cases of stomach cancer in United States, did not find significant differences in OS between SRC and NSRC adenocarcinomas (18).

Our findings were similar to those previously reported by Rougier et al. (32) who found no differences in survival in SRC adenocarcinoma despite a lower response rate to chemotherapy. The low response rate of SRC adenocarcinoma to chemotherapy may be explained by the more frequent presence of peritoneal involvement. In our study, peritoneal carcinosis was observed in $68.4 \%$ in SRC group and $30.8 \%$ in NSRC group. The peritoneal response rate is less than $14 \%(33,34)$. The peritoneal surface chemotherapy concentration is much lower than blood chemotherapy concentration after intravenous administration. The intraperitoneal (i.p.) administration of chemotherapy could be interesting. Ideal drugs for i.p. chemotherapy have high therapeutic index: high concentration in peritoneal cavity, high penetration in peritoneal nodules and low systemic concentrations. This difference in distribution is expressed by the area under the curve (AUC) ratios of i.p. versus blood exposure. Mitoxantrone, doxorubicin, 5-FU, gemcitabine, docetaxel and paclitaxel had an AUC i.p./intravenous (i.v.) of 115-255, 230, 250, 500, 552 and 1,000 respectively (35). Paclitaxel and docetaxel are the best drugs for i.p. treatment. Thus, i.p. chemotherapy can be evaluated in association with i.v. chemotherapy in selected patients with isolated peritoneal carcinosis of SRC carcinomas.

Current chemotherapy schedules do not seem effective enough on gastric cancer with SRC. In advanced disease, chemotherapy is the only treatment used. To improve the results in patients with SRC adenocarcinoma, it is necessary to perform prospective trials dedicated to this population. Targeted therapies currently in development seem an interesting line of research. A prospective randomised double-blind, phase III trial has evaluated bevacizumab plus chemotherapy in locally advanced and metastatic adenocarcinoma of the stomach (The Avastin in Gastric Cancer (AVAGAST) trial) (36). Bevacizumab was associated 
with a significantly increased PFS (6.7 vs. 5.3 months, $\mathrm{HR}=0.80 ; p=0.003$ ) without improvement of OS, which was the primary end-point of the trial (12.1 vs. 10.1 months, $\mathrm{HR}=0.87 ; p=0.1)$. An unplanned subset analysis of the AVAGAST study (37) suggested a benefit in the subset of non-Asians with diffuse or distal disease ( $H R=0.67$; $95 \% \mathrm{CI}=0.52-0.88)$. These data need to be confirmed in prospective studies specifically targeting this population.

The mammalian target of rapamycin (mTOR) is another target that has been tested in gastric cancer. Indeed, phosphomTOR is expressed in $60 \%$ of intestinal and $64 \%$ of diffusetype gastric adenocarcinomas (38). Everolimus, an oral mTOR inhibitor, was evaluated in an international phase III in previously treated advanced gastric cancer (39). Median OS was not improved by everolimus compared to best supportive care (5.4 months vs. 4.3 months, HR=0.90; $p=0.124)$. The subgroup analysis showed no benefit of everolimus for the diffuse-type gastric adenocarcinomas. Molecular studies of the diffuse-type gastric cancers are necessary to highlight new molecular targets.

Recently, ramucirumab, a monoclonal antibody against vascular endothelial growth factor receptor-2 (VEGFR-2) antagonist, has proven its benefit in second-line versus placebo in oesogastric adenocarcinomas with improved overall survival (5.2 months vs. 3.8 months, $\mathrm{HR}=0.78 ; p=0.047$ ) (41). In subgroup analysis, the diffuse-type of adenocarcinomas seemed to benefit significantly from this new anti-angiogenic therapy $(\mathrm{HR}=0.56)$. Ramucirumab seems also promising in second-line treatment in association with paclitaxel (42). This agent is currently assessed in first-line in association to chemotherapy.

A potential weakness of the present study was its retrospective nature, although it was performed on large series of patients treated in Europe. Another limitation is the absence of systematic reassessment of histological slides. Yet, Piessen et al. performed a re-assessment by a blinded pathologist on 33 slides of gastric adenocarcinomas in the University Hospital of Lille, France, which was the main centre of the present study (40). There was a high concordance rate of $93.9 \%$.

To conclude, our study indicated, in terms of response rate and survival, that patients with SRC gastric or oesogastric junction adenocarcinoma seemed to benefit less from chemotherapy and that the presence of SRC was not by itself an independent prognostic factor for survival.

\section{References}

1 Parkin DM, Pisani P and Ferlay J: Estimates of the worldwide incidence of eighteen major cancers in 1985. Int J Cancer 54(4): 594-606, 1993.

2 Parkin DM, Bray FI and Devesa SS: Cancer burden in the year 2000. The global picture. Eur J Cancer 37(Suppl 8): S4-S66, 2001.

3 Parkin DM: International variation. Oncogene 23(38): 63296340, 2004.
4 Diehl JT, Hermann RE, Cooperman AM and Hoerr SO: Gastric carcinoma. A ten-year review. Ann Surg 198(1): 9-12, 1983.

5 Lauren P: The two histological main types of gastric carcinoma: diffuse and so-called intestinal-type carcinoma. Acta Pathol Microbiol Scand 64: 31-49, 1965.

6 Watanabe H, Jass JR and Sobin LH: Histological typing of oesophageal and gastric tumours. WHO international histological classification of tumors, 2nd edition. Berlin: Springer-Verlag; 1990.

7 Henson DE, Dittus C, Younes M, Nguyen H and Albores-Saavedra J: Differential trends in the intestinal and diffuse types of gastric carcinoma in the United States, 1973-2000: increase in the signet ring cell type. Arch Pathol Lab Med 128(7): 765-770, 2004.

8 Fayçal J, Bessaguet C, Nousbaum JB, Cauvin JM, Cholet F, Bideau K, Robaszkiewicz M and Gouérou H: Epidemiology and long term survival of gastric carcinoma in the French district of Finistere between 1984 and 1995. Gastroentérologie Clin Biol 29(1): 23-32, 2005.

9 Arsène D, Chomontowski J, Pottier D, Rougereau A, Launoy G and Gignoux M: Epidemiology and prognosis of gastric carcinomas at the province of Calvados. A 10-year study. Gastroentérologie Clin Biol 19(10): 797-803, 1995.

10 Crew KD and Neugut AI: Epidemiology of gastric cancer. World J Gastroenterol 12(3): 354-362, 2006.

11 Kunisaki C, Shimada H, Nomura M, Matsuda G, Otsuka Y and Akiyama $\mathrm{H}$ : Therapeutic strategy for signet ring cell carcinoma of the stomach. Br J Surg 91(10): 1319-1324, 2004.

12 Otsuji E, Yamaguchi T, Sawai $\mathrm{K}$ and Takahashi T: Characterization of signet ring cell carcinoma of the stomach. $\mathrm{J}$ Surg Oncol 67(4): 216-220, 1998.

13 Ha TK, An JY, Youn HK, Noh JH, Sohn TS and Kim S: Indication for endoscopic mucosal resection in early signet ring cell gastric cancer. Ann Surg Oncol 15(2): 508-513, 2008.

14 Piessen G, Messager M, Leteurtre E, Triboulet JP and Mariette C: Signet ring cell histology is an independent predictor of poor prognosis in gastric adenocarcinoma regardless of tumoral clinical presentation. Ann Surg 250(6): 878-887, 2009.

15 Kim JP, Kim SC and Yang HK: Prognostic significance of signet ring cell carcinoma of the stomach. Surg Oncol 3(4): 221-227, 1994.

16 Li C, Kim S, Lai JF, Hyung WJ, Choi WH, Choi SH and Noh SH: Advanced gastric carcinoma with signet ring cell histology. Oncology 72(1-2): 64-68, 2007.

17 Kim DY, Park YK, Joo JK, Ryu SY, Kim YJ, Kim SK and Lee $\mathrm{JH}$ : Clinicopathological characteristics of signet ring cell carcinoma of the stomach. ANZ J Surg 74(12): 1060-1064, 2004.

18 Theuer CP, Nastanski F, Brewster WR, Butler JA and AntonCulver H: Signet ring cell histology is associated with unique clinical features but does not affect gastric cancer survival. Am Surg 65(10): 915-921, 1999.

19 Messager M, Lefevre JH, Pichot-Delahaye V, Souadka A, Piessen $G$ and Mariette $C$ : The impact of perioperative chemotherapy on survival in patients with gastric signet ring cell adenocarcinoma: A multicenter comparative study. Ann Surg 254(5): 684-693, 2011.

20 Eisenhauer EA, Therasse P, Bogaerts J, Schwartz LH, Sargent D, Ford R, Dancey J, Arbuck S, Gwyther S, Mooney M, Rubinstein L, Shankar L, Dodd L, Kaplan R, Lacombe D and Verweij J: New response evaluation criteria in solid tumours: Revised RECIST guideline (version 1.1). Eur J Cancer 45(2): 228-247, 2009. 
21 Cancer Therapy Evaluation Program, Common Terminology Criteria for Adverse Events, Version 3.0, DCTD, NCI, NIH, DHHS March 31, 2003 (http://ctep.cancer.gov), Publish Date: August 9, 2006.

22 Murad AM, Santiago FF, Petroianu A, Rocha PR, Rodrigues MA and Rausch M: Modified therapy with 5-fluorouracil, doxorubicin, and methotrexate in advanced gastric cancer. Cancer 72(1): 37-41, 1993.

23 Pyrhönen S, Kuitunen T, Nyandoto P and Kouri M: Randomised comparison of fluorouracil, epidoxorubicin and methotrexate (FEMTX) plus supportive care with supportive care alone in patients with non-resectable gastric cancer. Br J Cancer 71(3): 587-591, 1995.

24 Wagner AD, Unverzagt S, Grothe W, Kleber G, Grothey A, Haerting J and Fleig WE: Chemotherapy for advanced gastric cancer. Cochrane Database Syst Rev (3):CD004064, 2010.

25 Cunningham D, Allum WH, Stenning SP, Thompson JN, Van de Velde CJ, Nicolson M, Scarffe JH, Lofts FJ, Falk SJ, Iveson TJ, Smith DB, Langley RE, Verma M, Weeden S and Chua YJ: Perioperative chemotherapy versus surgery alone for resectable gastroesophageal cancer. N Engl J Med 355(1): 11-20, 2006.

26 Taghavi S, Jayarajan SN, Davey A and Willis AI: Prognostic significance of signet ring gastric cancer. J Clin Oncol 30(28): 3493-3498, 2012.

27 Jiang C-G, Wang Z-N, Sun Z, Liu F-N, Yu M and Xu H-M: Clinicopathologic characteristics and prognosis of signet ring cell carcinoma of the stomach: Results from a Chinese monoinstitutional study. J Surg Oncol 103(7): 700-703, 2011.

28 Tong J, Sun Z, Wang Z, Zhao YH, Huang BJ, Li K, Xu Y and $\mathrm{Xu} \mathrm{HM}$ : Early gastric cancer with signet-ring cell histologic type: Risk factors of lymph node metastasis and indications of endoscopic surgery. Surgery 149(3): 356-363, 2011.

29 Hyung WJ, Noh SH, Lee JH, Huh JJ, Lah KH, Choi SH and Min JS: Early gastric carcinoma with signet ring cell histology. Cancer 94(1): 78-83, 2002.

30 Maehara Y, Sakaguchi Y, Moriguchi S, Orita H, Korenaga D, Kohnoe S and Sugimachi K: Signet ring cell carcinoma of the stomach. Cancer 69(7): 1645-1650, 1992.

31 Yokota T, Kunii Y, Teshima S, Yamada Y, Saito T, Kikuchi S and Yamauchi H: Signet ring cell carcinoma of the stomach: A clinicopathological comparison with the other histological types. Tohoku J Exp Med 186(2): 121-130, 1998.

32 Rougier P, Ducreux M, Mahjoubi M, Pignon JP, Bellefqih S, Oliveira J, Bognel C, Lasser P, Ychou M and Elias D: Efficacy of combined 5-fluorouracil and cisplatinum in advanced gastric carcinomas. A phase II trial with prognostic factor analysis. Eur J Cancer 30A(9): 1263-1269, 1994.

33 Yonemura Y, Endou Y, Sasaki T, Hirano M, Mizumoto A, Matsuda T, Takao N, Ichinose M, Miura M and Li Y: Surgical treatment for peritoneal carcinomatosis from gastric cancer. Eur J Surg Oncol 36(12): 1131-1138, 2010.
34 Ross P, Nicolson M, Cunningham D, Valle J, Seymour M, Harper P, Price T, Anderson H, Iveson T, Hickish T, Lofts F and Norman A: Prospective randomized trial comparing mitomycin, cisplatin, and protracted venous-infusion fluorouracil (PVI 5FU) With epirubicin, cisplatin, and PVI 5-FU in advanced esophagogastric cancer. J Clin Oncol 20(8): 1996-2004, 2002.

35 Van der Speeten K, Stuart OA and Sugarbaker PH: Using pharmacologic data to plan clinical treatments for patients with peritoneal surface malignancy. Curr Drug Discov Technol 6(1): 72-81, 2009.

36 Ohtsu A, Shah MA, Van Cutsem E, Rha SY, Sawaki A, Park SR, Lim HY, Yamada Y, Wu J, Langer B, Starnawski M and Kang YK: Bevacizumab in combination with chemotherapy as firstline therapy in advanced gastric cancer: a randomized, doubleblind, placebo-controlled phase III study. J Clin Oncol 29(30): 3968-3976, 2011.

37 Manish A and Shah MA: Survival analysis according to disease subtype in AVAGAST: First-line capecitabine and cisplatin plus bevacizumab or placebo in patients with advanced gastric cancer. J Clin Oncol (suppl 4; abstr 5), 2012.

38 Lang SA, Gaumann A, Koehl GE, Seidel U, Bataille F, Klein D, Ellis LM, Bolder U, Hofstaedter F, Schlitt HJ, Geissler EK and Stoeltzing O: Mammalian target of rapamycin is activated in human gastric cancer and serves as a target for therapy in an experimental model. Int J Cancer J Int Cancer 120(8): 18031810, 2007.

39 Ohtsu A, Ajani JA, Bai Y-X, Bang YJ, Chung HC, Pan HM, Sahmoud T, Shen L, Yeh KH, Chin K, Muro K, Kim YH, Ferry D, Tebbutt NC, Al-Batran SE, Smith H, Costantini C, Rizvi S, Lebwohl D and Van Cutsem E: Everolimus for previously treated advanced gastric cancer: Results of the randomized, double-blind, phase III GRANITE-1 study. J Clin Oncol 31(31): 3935-3943, 2013.

40 Piessen G, Amielh D, Messager M, Vinatier E, Leteurtre E, Triboulet JP and Mariette C: Is pretreatment endoscopic biopsy a good predictor of signet ring cell histology in gastric carcinoma? World J Surg 36(2): 346-354, 2012.

41 Fuchs CS, Tomasek J, Yong CJ, Dumitru F, Passalacqua R, Goswami C, Safran H, dos Santos LV, Aprile G, Ferry DR, Melichar B, Tehfe M, Topuzov E, Zalcberg JR, Chau I, Campbell W, Sivanandan C, Pikiel J, Koshiji M, Hsu Y, Liepa AM, Gao L, Schwartz JD and Tabernero J: Ramucirumab monotherapy for previously treated advanced gastric or gastrooesophageal junction adenocarcinoma (REGARD): An international, randomised, multicentre, placebo-controlled, phase III trial. Lancet 383(9911): 31-39, 2014.

Received August 29, 2016

Revised September 16, 2016

Accepted September 19, 2016 